\title{
Ética e gestão escolar democrática dentro do estado neoliberal
}

\author{
Ethics and democratic school management within the neoliberal state \\ Ética y gestión escolar democrática dentro del estado neoliberal
}

Recebido: 28/09/2021 | Revisado: 03/10/2021 | Aceito: 07/10/2021 | Publicado: 10/10/2021

\author{
Astrid Pantoja das Neves Matos \\ ORCID: https://orcid.org/0000-0003-1343-3924 \\ Universidade Estadual de Mato Grosso do Sul, Brasil \\ E-mail: astriddasneves@hotmail.com \\ Fabiana Parron Bergamo \\ ORCID: https://orcid.org/0000-0001-6054-776X \\ Universidade Estadual de Mato Grosso do Sul, Brasil \\ E-mail: faparron@yahoo.com.br
}

\begin{abstract}
Resumo
Este artigo é resultado de um estudo bibliográfico que pretende analisar a educação numa perspectiva democrática no contexto do estado neoliberal, com objetivo de refletir a ética e a organização da gestão escolar dentro desse espaço. Analisa-se através de um breve histórico, as lutas para a redemocratização do país, que influênciaram na elaboração da Constituição Federal de 1988, e também aquelas que tinham como objetivo melhorar o meio educacional, exigindo mudanças para novas práticas de tratamento das relações educacionais. Ressalta-se neste estudo, o princípio da gestão democrática do ensino público, contemplada no artigo 206, inciso VI, da Costituição Federal de 1988, a expressão na forma da lei, acrescida no inciso VI, que delegou aos sistemas de ensino, uma legislação complementar, fato que levou a muita discussão por parte dos movimentos de luta do setor da educação sobre essa conquista parcial. Com o surgimentos de novas organizações educacionais, que colocavam em discussão a prática democrática e pedagógica nas escolas públicas brasileiras, e, mesmo após a regulamentação da gestão democrática nas escolas, ainda havia um anseio por implementações de ações com mais participação da sociedade nas tomadas de decisões, necessitando de uma gestão escolar, ativa, ética e democrática, garantindo de fato uma nova postura educacional.
\end{abstract}

Palavras-chave: Educação; Comportamento; Gestão escolar.

\begin{abstract}
This article is the result of a bibliographical study that intends to analyze education in a democratic perspective in the context of the neoliberal state, aiming to reflect the ethics and organization of school management within this space. It analyzes, through a brief history, the struggles for the redemocratization of the country, which influenced the elaboration of the Federal Constitution of 1988, and also those that aimed to improve the educational environment, demanding changes to new practices in the treatment of educational relations. This study emphasizes the principle of democratic management of public education, contemplated in article 206, item VI, of the Federal Constitution of 1988, the expression in the form of the law, added in item VI, which delegated legislation to the education systems. complementary, a fact that led to much discussion on the part of the struggle movements in the education sector about this partial achievement. With the emergence of new educational organizations, which brought into discussion the democratic and pedagogical practice in Brazilian public schools, and even after the regulation of democratic management in schools, there was still a yearning for implementation of actions with more participation of society in the taking of decisions, requiring a school management, active, ethical and democratic, ensuring in fact a new educational posture.
\end{abstract}

Keywords: Education; Behavior; School management.

\section{Resumen}

Este artículo es el resultado de un estudio bibliográfico que pretende analizar la educación en una perspectiva democrática en el contexto del estado neoliberal, buscando reflejar la ética y organización de la gestión escolar dentro de este espacio. Analiza, a través de una breve historia, las luchas por la redemocratización del país, que influyeron en la elaboración de la Constitución Federal de 1988, y también aquellas que apuntaron a mejorar el ambiente educativo, exigiendo cambios a nuevas prácticas en el tratamiento de las relaciones educativas. . Este estudio enfatiza el principio de gestión democrática de la educación pública, contemplado en el artículo 206, inciso VI, de la Constitución Federal de 1988, la expresión en forma de ley, agregada en el inciso VI, que delega la legislación a los sistemas educativos. , hecho que generó mucha discusión por parte de los movimientos de lucha del sector educativo sobre este logro parcial. Con el surgimiento de nuevas organizaciones educativas, que pusieron en discusión la práctica democrática y pedagógica en las escuelas públicas brasileñas, e incluso después de la regulación de la gestión democrática en las escuelas, aún existía el anhelo de implementación de acciones con mayor participación de la sociedad en la toma de 
decisiones. de decisiones, requiriendo una gestión escolar, activa, ética y democrática, asegurando de hecho una nueva postura educativa.

Palabras clave: Educación; Comportamiento; Gestión escolar.

\section{Introdução}

O princípio de gestão democrática, discutido pelos profissionais da educacão durante a década de 1980 no Brasil e comtemplado na Costituição Federal de 1988 (Brasil, 1988), é a temática desse artigo. Trata-se ainda de estudos e pesquisas referente à ética e gestão escolar democrática no estado neoliberal. Com os desafios enfrentados pela educação em nosso país, essa temática tem se tornado mais presente no cotidiano escolar, reflexões teóricas são necessárias para compreender esse processo de tomadas de decisões pelo coletivo, promovendo reestruturação no sistema escolar.

A década de 1970 foi um período importante no Brasil, com a atuação de vários movimentos de resistência ao governo e a construção das bases para a redemocratização no país. Surgiram novas organizações destacando-se o Movimento de União dos Professores (MUP) em 1976; o Movimento de Lutas por Creches em 1979; Movimento no Campo, que deu origem ao Movimento dos Trabalhadores Rurais sem Terra (MST) em 1979; e em 1973 ocorreu a transformação da Associação dos Professores do Ensino Secundário e Normal Oficial do Estado de São Paulo (Apeoesp), que antes já atuava com outro nome (Gohn, 2019).

As lutas pela educação também continuaram na década de 1980, quando ocorreu a fundação da Associação Nacional de Professores do Ensino Superior (Andes), em 1981 com a formação do Fórum Nacional de Defesas da Escola Pública, em 1987. Estas tiveram papel importante na elaboração dos artigos relativos a educação no processo constituinte do país. Outro grande movimento vivenciado nesta década, foi o movimento das Diretas Já em 1984 (Gohn, 2019).

Gohn (2019, p.192), afirma:

O tema dos direitos é fundamental porque ele dá universalidade às questões sociais, aos problemas econômicos e às políticas públicas, atribuindo-lhes caráter emancipatório. É a partir dos direitos que fazemos o resgate da cultura de um povo e de uma nação.

O anseio pelo processo educativo coletivo, os movimentos sociais e as lutas educativas no Brasil, vem ao longo dos anos estabelecendo discussões e promovendo reformulações no sistema escolar do país. Muitos desses movimentos, a partir da década de 1970, retratam segundo Gohn (2019, p.197):

Um período de resistência e construção das bases para a redemocratização: retomada da organização sindical, surgimento de movimentos de comunidade de base (CEBs) nos bairros, movimento pela Anistia, reorganização partidária e criação de movimentos sociais que vieram a ser marcos no processo constituinte dos anos de 1980.

Assim, ocorreu também um importante movimento em 1988, que foi o Movimento em Defesa da Escola Pública. "Esse movimento surgiu da articulação em torno da Constituinte, em seu capítulo da Educação, e se fez necessário ante a exigência constitucional de elaboração de uma nova Lei de Diretrizes e Bases da Educação Nacional” (Gohn, 2019,p. 202).

A partir dos anos 1990, surgiram outras formas de organização popular, como a constituição de Fóruns Nacionais de Luta pela Educação. Nesses encontros nacionais, se definiam metas e objetivos estratégicos para os problemas sociais diagnosticados, firmando parceria com a sociedade civil organizada e poder público (Gohn, 2019).

Ainda no inicio da década de 1990, o Movimento Ética na Política, foi um grande movimento ocorrido naquela época. Gohn (2019, p. 205) aponta que esse movimento: 
Teve grande importância histórica porque contribuiu, decisivamente, para a deposição, por meio do processo democratico, de um presidente da República por atos de corrupção, fato até então inedito no país; além disso, colaborou na época, para o ressurgimento do movimento dos estudantes com o novo perfil de atuação , os "cara- pintadas".

Brasil (1996). A Lei 9.394/96 - Lei de Diretrizes e Bases da Educação Nacional, em seu art.3º afirma que a escola é um espaço público de natureza democrática e coletiva. Nesta perspectiva a partir de 1990, inicia-se também as reflexões vivenciada na ética de compartilhar decisões no cenário escolar.

A ética na gestão escolar entra de contramão ao do neoliberalismo, evidenciando pensamentos compartilhados e coletivos no contexto social dentro do ambiente escolar. Busca ativar uma sociedade interessada em participar das decisões tomadas dentro das escolas, contribuindo para que os grupos coletivos, movimentos e organizações se posicionem, gerando uma gestão democrática ativa e consciente de seus direitos e deveres.

Segundo Pinheiro (2015, p. 87), “Os Movimentos Sociais (MS) são organizações estruturadas com finalidade de criar formas de associação entre pessoas e entidades que tenham interesse em comum, para a defesa de certos objetivos, e que atuam em ambientes públicos”. No entanto, percebe-se que a gestão democrática foi uma luta dos movimentos sociais, luta por uma educação inovadora, luta por conquista dos direitos sociais dos cidadãos. Pressupoe-se que a gestão escolar possua uma ética frente as ações educativas, que precisam ser norteadas com objetivos, estratégias e decisões do coletivo.

\section{Metodologia}

A metodologia utilizada para este artigo foi um estudo bibliográfico sobre a temática proposta. Os dados obtidos foram consultados em livros, revistas científicas, bibliotecas digitais, teses, pesquisas e artigos científicos. Determinou-se as palavraschaves a serem buscadas, educação, comportamento e gestão escolar. O critério estabelecido para a seleção foi de publicações que tratassem do tema gestão escolar democrática na educação. Para a elaboração desse material, utilizou-se muitas plataformas on-line e gratuitas, buscando trabalhos acadêmicos que versassem sobre a gestão escolar democrática. As buscas foram realizadas no período de 01 de julho a 30 de setembro de 2021. A partir das leituras, apontamentos por meio de fichas de citações, resumos, comentários e análise do tema em questão, foi possível identificar a abordagem dos temas relacionados no desenvolvimento do estudo.

A escolha do tema para este artigo se deu por meio de leitura de trabalhos e pesquisas de vários autores que trazem reflexões e discussões sobre ética e gestão escolar, destacando autores como Paro (2016), Vieitez e Dal Ri (2010), Oliveira (2015) Fernandes (2018), entre outros. Sobre a pesquisa bibliográfica, Lima e Mioto (2007, p. 41), afirmam que:

A pesquisa bibliográfica tem sido um procedimento bastante utilizado nos trabalhos de caráter exploratório-descritivo, reafirma-se a importância de definir e de expor com clareza o método e os procedimentos metodológicos (tipo de pesquisa, universo delimitado, instrumento de coleta de dados) que envolverão a sua execução, detalhando as fontes, de modo a apresentar as lentes que guiaram todo o processo de investigação e de análise da proposta.

Ainda para Lima e Mioto (2007, p. 38), “A pesquisa bibliográfica em um conjunto ordenado de procedimentos busca soluções, atento ao objeto de estudo, e que por isso não pode ser aleatório". Todo estudo científico requer uma pesquisa bibliográfica, necessária para a fundamentação teórica, para justificativas e resultados obtidos do que esta sendo tratado. Com o levantamento do material, foi delimitado a base temporal, selecionando produções publicadas sobre a construção de gestão escolar democrática nos anos de 1980 e 1990, no Brasil. O método utilizado para este artigo, será de interpretação das informações obtidas, análise e elaboração de material frente a este estudos. É por meio da pesquisa bibliográfica que temos acesso do que foi publicado sobre a temática que propõe-se em estudar.

Nesse caso, pretende-se durante o decorrer desse artigo, trazer as informações obtidas, analisando-as e refletindo sobre 
os desafios de gerir uma escola diante do principio da gestão democrática.

\section{Resultados e Discussão}

Para uma educação transformadora, é preciso primeiramente transformar a escola em um espaço de discussão e participação. É preciso promovor a participarção efetiva com quem faz parte dela. Considerando fundamental que os problemas e os projetos escolares sejam resolvidos e elaborados pela comunidade escolar, valorizando a tomada de decisões do coletivo, faz-se necessário, que seus usuários assim como os demais segmentos que compõem a comunidade escolar, participem desses grupos, organizados e com objetivos claros destinados a educação escolar.

A fim de valorizar a participação dos alunos, vale ressaltar também o que dizem Vietez e Dal Ri (2011, p.133): “No Brasil, nas décadas de 1950 e 1960, no bojo do Movimento pela Revolução Brasileira (MRB), a participação dos atores da educação esteve representada praticamente pelo movimento estudantil (ME), notadamente das universidades públicas".

Com a ditadura militar em 1964, instaurada no Brasil, o movimento social (MS) sofreu várias ações de repressão pelo governo, mas permaneceu atuando escondido, com exceção do movimento estudantil que praticava publicamente suas lutas. Com a publicaçãodo Decreto- Lei 477 (Brasil, 1969) que instituiu o Ato Institucional n. 5 (AI-5), os estudantes, foram coagidos, como forma de repressão. E muitos conflitos e movimentos vivenciados nesta época e gerados pelos operários, buscavam acabar com a ditadura, coma exploração econômica e lutava por uma república democrática (Vieitez \& Dal Ri, 2011).

Dessa forma, diante deste contexto, professores e funcionários deram uma nova dimensão à atuação politica nos movimentos, engrossando a luta conta a ditadura e pela volta do estado de direito. Também defenderam o ensino público gratuito e apresentaram uma proposta de gestão democrática na escola, neste sentido a educação passou a ter uma importancia maior na pauta politica de partidos, sindicatos e demais organizações (Vieitez \& Dal Ri ,2011).

Por conta disso, os debates avançaram no período constituinte, resultaram na promulgação da Constituição Federal de 1988 (Brasil, 1988), e a educação foi considerada um direito social, direito de todos e dever do Estado e da família, tratado no art. 205. No art. 206, inciso VI, retrata-se que o ensino será ministrado com base no princípio de gestão democrática do ensino público.

Para Vieitez e Dal Ri (2010, p. 112):

O princípio da gestão democrática na escola pública figurou na Constituição promulgada em 1988, que foi o ato legal de maior estatura a sedimentar a flexão histórica realizada com a passagem da Ditadura ao regime democrático. Esse preceito foi reafirmado na Lei de Diretrizes e Bases da Educação Nacional (LDB), n. 9394, sancionada em 1996, na qual estão previstas as participações dos profissionais da educação na elaboração do projeto pedagógico da escola e das comunidades escolar e local em conselhos escolares e equivalentes (art. 14º).

Mesmo com o princípio de gestão democrática no ensino trazido pela Constituição Federal (Brasil,1988), percebe-se que a influência neoliberal é bastante forte no país, e a educação vem sendo alvo para a disseminação dos ideais neoliberais. "O neoliberalismo defende o não controle do estado na economia" (Silva, 2010, p.22).

Ainda para Silva (2010, p.22):

No discurso neoliberal a educação como um todo passa a ingressar no mercado capitalista funcionando logo à sua semelhança, deixando-se assim de ser parte do campo social e político, os conteúdos políticos da cidadania, foram substituído pelos direitos do consumidor.

No entanto, com o fim do regime militar e a crise econômica na década de 1980, a ideologia privatista fica ainda mais em evidência, o privado ressalta a lógica neoliberal à administração do ensino no Brasil. Percebe-se no entanto que a escola 
pública reproduz as estruturas existentes, prepara o indivíduo, tecnicamente para a demanda dessa sociedade. Sem se preocupar com à formação pessoal, ou à resistência à exploração do trabalho. Vale a pena acrescentar a afimação de Bruno (2011, p.547):

Os sistemas nacionais de educação foram, então, criados a partir dos modelos burocráticos vigentes, inspirados, de início, na teoria clássica da administração para, em seguida, serem reorganizados ao longo do século XX, tendo como referência os sucessivos modelos de gestão e administração empresarial.

Dessa forma, frente a um cenário empresarial, a educação se torna relevante, porque a sociedade deseja mão de obra qualificada, preparada para competir no mercado. Nesse sentido a educação passa a ser de interesse, pois exige-se técnicas de organização e estratégias para garantir o trabalho na sociedade de modo capitalista. Harvey (2008,p. 27) afirma :

Podemos, portanto, interpretar a neoliberalização seja como um projeto utópico de realizar um plano teórico de reorganização do capitalismo internacional ou como um projeto político de restabelecimento das condições de acumulação do capital e de restauração do poder das elites econômicas.

Vivemos em uma sociedade onde o sistema econômico é o capitalismo, que tem objetivo de gerar lucro e acumular riquezas, por meio dos meios de produção e propriedade privada. Essa economia de mercado também predomina o domínio da classe burguesa sobre a classe trabalhadora, que vende sua força de trabalho e é explorada pelas formas de produção. “ Um modo de produção é não somente uma tecnologia, mas uma organização social da atividade produtiva; e um modo de exploração é um a relação de poder" (Wood, 2011, p.33).

Assim a educação, nesta sociedade terá a função de promover a reprodução dos ideais capitalistas, de formar individuos para atuarem nesta sociedade, transmitindo valores e habilidades, esses individuos serão os trabalhadores, e que conformarão com ordem burguesa.

A Lei de Diretrizes e Bases da Educação Nacional, foi sancionada em 20 de dezembro de 1996 - Lei 9.394/96 (Brasil, 1996) e retrata em seu art. $3^{\circ}$ inciso VIII, o princípio de gestão democrática do ensino público. Esse princípio demostra que a escola é um espaço público, de natureza democrática e de participação coletiva nas tomadas de decisões.

Contudo, essa gestão que é evidenciada na LDB- Lei 9.394/96 (Brasil, 1996), deveria se contrapor a ética e politicamente às estratégias neoliberal e capitalista no Brasil. Percebe-se que a gestão democrática não deveria atender as questões e interesses dos grupos dominantes, econômicos e políticos, luta-se para que a gestão democrática defenda as questões coletivas e propicie as tomadas de decisões escolares. Mas diante da estrutura do sistema capitalista que temos na sociedade brasileira, e as relações de poder existentes, percebe-se que a educação no país esta a serviço dos interesses desse sistema econômico, o que dificulta a construção de uma educação voltada à prática democrática e inovadora.

É preciso pensar em uma educação voltada para esta prática, sobre este ponto, Lukács (2013, p. 178) considera: “Assim sendo, a problemática da educação remete ao problema sobre o qual está fundada: sua essência consiste em influenciar os homens no sentido de reagirem a novas alternativas de vida do modo socialmente intencionado."

Alves e Barbosa (2020 p. 8) apresentam que “ A gestão escolar não se reduz a questões de buracracia e administração, são mais que tudo, práticas educacionais. Práticas estas que envolvem valores, ações, percepções e que produzem aprendizagens para além dos muros físicos, produzem aprendizadfos sociais".

Para tanto, precisa-se de uma educação com função transformadora, com projetos sociais bem definidos, influenciando os individuos a lutarem por sua liberdade, tendo consciência de classe e defendendo no campo da econômia, da política, do intelecto e da religião, projetos que garantam a igualdade de direitos. Uma educação que confronta a democracia liberal burguesa. Frentre a tudo isso, Fernandes (2018, p.23) , acredita que "A articulação entre educação e democracia, enquanto mediação entre sociedade, Estado e educação, no caso brasileiro, tem sido a materialdade dessa disputa de projeto social mais amplo". 
Como afirma Paro (2018, p.25): “Trata-se em outras palavras, da necessidade de ter a educação par a democracia como componente fundamental da qualidade do ensino".

O neoliberalismo baseia-se nos princípios de competição, desigualdades e eficiência, dessa forma, a ética vai reconfigurando as relações sociais e permanecendo a ideia de que tudo é possível. Faz-se necessário discutir essas relações, tanto social quanto política, resgatando um dialógo crítico, argumentativo em prol de uma sociedade com mais condições de escolhas. Deve-se ter por base a ética, promovendo a democratização da informação e da cultura, condição necessária para a formação de identidade.

A gestão escolar vista em leis, como democrática-participativa, deve provocar reflexões e debates sobre essa educação com função transformadora e também sobre a prática vivenciada e os modelos empresariais de gestão encontrados nas escolas públicas. A ideologia neoliberal no Brasil, teve seu enfoque maior na década de 1990 e tem demostrado formas diferenciadas sobre a prática de gestão democrática no país.

No entanto, o que se espera é uma escola onde o gestor escolar, no cotidiano, permita que os individuos assumam seus papéis com autonomia e responsabilidade, e que esse gestor, também exerça, as questões administrativas, financeiras e pedagógicas. Deve, no exercício da função, promover ações que implicam aos sujeitos posturas e tomadas de decisões diante das situações conflitantes e dos desafios cotidianos, promovendo através do diálogo, a prática de princípios de valores, possibilitando de forma ética, a resolução e a execução de procedimentos decididos pelo coletivo.

Assim, superando o individualismo e a educação excludente, as tomadas de decisões coletivas, contribiu também com a preparação dos alunos para a participação na sociedade e que "habitem os estudantes a terem expectativas de vida digna, de trabalho, de exercício da cidadania”, ressalta Cóssio (2006).

Paro (2016, p.7-8), afirma ainda que:

[..] administrar uma escola pública não se reduz à aplicação de uns tantos métodos e técnicas, importados, muitas vezes, de empresas que nada têm a ver com objetivos educacionais. A administração escolar é portadora de uma especificidade que a diferencia da administração especificamente capitalista, cujo objetivo é o lucro, mesmo em prejuízo da realização humana implícita no ato educativo. Se administrar é usar racionalmente os recursos para a realização de fins determinados, administrar a escola exige a permanente impregnação de seus fins pedagógicos na forma de alcançá-los.

Com a necessidade de mudança na forma de gerir a escola, e frente aos princípios capitalistas, a partir de 1990, começaram as reflexões sobre uma gestão democrática vivenciada na ética de compartilhar decisões. Afirma Fernandes (2018, p.17):

Disso configurou, por um lado, a descrença nos processos de gestão democrática por parte de setores sociais envolvidos, quando se vislumbram somente seus resultados. Por outro lado, configurou brechas para que o Estado neoliberal instalado a partir mesmo de 1989, que passou a conviver com as tradicionais concepções de Estado neoliberal, fosse imprimindo outros modelos de gestão na educação, identificados agora como de gestão compartilhada, gestão gerencial, tudo muito a gosto da Nova Gestão Pública promovida pelo estado gerencial.

Nesta perspectiva ser um gestor ético é trabalhar pensando na comunidade escolar, é se contrapor as idéias neoliberais e organizar ações e projetos que visam manter um bom convívio entre as pessoas em um ambiente escolar, compartilhar decisões, ouvir a opinião do outro e tomar decisões com o coletivo,proporcionando uma gestão democrática e participativa, modificando assim, os modelos de gestão gerencial praticado dentro da escola.

Segundo Aristóteles (1973), essas práticas, dizem respeito à conduta dos homens e aos fins que eles se propõem a atingir, seja como individuo ou como parte de uma sociedade política.

A ética levada em conta por Aquino (1999), aplica-se a tudo e em todos os lugares, portanto a ética são normas, regras de comportamento diretamente aplicadas no relacionamento interpessoal e insere-se em todas as atividades sociais. Em um 
ambiente escolar, pode-se observar sua ação nessas relações.

Dessa forma, Paro (2001, p. 51) coloca: "Falar, por conseguinte, em gestão escolar é ter presente o modo pelo qual, ao viabilizar a educação, a gestão possibilita o acesso do educando à ética, e à liberdade".

Percebe-se ainda que a interação entre professor, equipe pedagógica, família e aluno incide na autonomia da aprendizagem de nossas crianças, favorecendo uma gestão ética e a criticidade frente aos princípios morais de uma sociedade. Esta gestão ética pressupõe iniciativas capazes de se reinventar nos momentos de conflitos. Investir nas relações interpessoais nas instituições escolares e nas decisões coletivas é acreditar na humanidade, é compreender que errar faz parte do aprendizado, valorizando as pessoas com suas diferenças, os interesses dos grupos, construindo consciência do autoconhecimento de si mesmo para resolver conflitos e respeitando as tomadas de decisões do grupo.

Paro (2016, p.58-59), descreve:

Na perspectiva da participação dos diversos grupos na gestão da escola, parece que não se trata de ignorar ou minimizar a importância desses conflitos, mas de levar em conta sua existência, bem como suas causas e suas implicações na busca da democratização da gestão escolar, como condição necessária para a luta por objetivos coletivos de mais longo alcance, como o efetivo oferecimento de ensino de boa qualidade para a população.

Nesse caso, segundo Aristóteles (1973, p. 41), “o comportamento seria um fator distintivo da ética, assim, o modo de agir com os outros, consigo mesmo, frente aos que nos são caros, perante a humanidade e que nos constituímos como seres justos, como seres que praticam a temperança, a bondade".

Assim, nessa perspectiva, a atitude mais prudente e mais sábia seria lançar mão do que Aristóteles chama de justo meio evitando os extremos. Pensar o justo meio em educação seria prescrever a ação sensata aquilo que, nos temos de Aristóteles, “não é demais nem muito pouco" (Aristóteles, 1973).

Portanto, uma gestão democrática, associada à ética a qual direciona as condutas humanas, intervindo nas relações interpessoais nas instituições escolares, questões éticas que envolva as ações pedagógicas, fazendo parte do Projeto Político Pedagógico, que é um documento administrativo que rege todas as ações de uma gestão preocupada com seu fazer pedagógico, assegura o aprendizado dos seus alunos, e efetiva uma gestão moderna, gerando a participação de todos.

Filho, Maciel, Monteiro e Nantes (2019) ressaltam ainda que:

A escola é um espaço de socialização por excelência, que possibilita a crianças, adolescentes e aos profissionais da educação a construção de saberes necessária a vida cotidiana, bem como a convivência em um universo de trocas de experiências culturais oriundas do ambiente familiar.

Na visão de Vásquez (1996), a ética na gestão escolar exige uma análise histórico-dialético, não podendo ser considerada “como algo absoluto, sobre-humano ou intemporal, que existe em si ou por si, mas como um produto humano que somente existe, vale e se justifica como nexo de relações." (Vásquez, 1996, p.223). Nesse contexto o comportamento ético dentro das escolas não se valia apenas pelas ações, mas propriamente pelas relações entre o meio coletivo e os sujeitos. Faz-se necessário uma educação onde o conhecimento seja entrelaçado para a trasformação social. Ter conhecimento não apenas para ter condições de competitividade dentro da sociedade capitalista, mas ter conhecimento para constituir estratégias para equidade social. Contribuindo com nossas reflexões, sobre as relações do coletivo, Alves e Barbosa (2020, p.7), entende que " Para que o todo possa se compor, a gestão precisa de estratégias como a descentralização de serviços, autonomia, dialogicidade, participação, enfim, ações didático-pedagógicas que envolvam a todos em união".

Melo (1993, p. 28) retrata:

Na maioria dos países da America Latina, entre eles o Brasil, o modelo educativo que serviu a uma etapa de 
desenvolvimento foi o de uma eleite altamente educada e informada e de uma massa escolarizada apenas para dar conta das tarefas elementares de uma industrialização tardia e dependente.

Nesta perspectiva percebe-se a face produtiva do neoliberalismo, em que a chamada livre concorrência, estimula a qualidade e a produtividade. Já Paro (2001), vem demostrando que os princípios que norteiam a "qualidade total” nas escolas, adotaram parâmetros neoliberais a gestão das escolas e faz uma crítica sobre a aplicação da lógica do mercado aos assuntos educacionais. Esse modelo gerencial na gestão escolar, é sustentado pela ideologia neoliberal. Muito distante de uma gestão democrática, que se valoriza as relações sociais e coletivas.

Assim, “[...] quando o liberalismo fala de liberdade de mercado, ele está-se referindo à necessidade de se deixar que as relações sociais se deem de acordo com as regras do mercado sem que se interfira em seu normal desenvolvimento.” (Paro, 2001, p. 15).

Afirma também Oliveira (2015, p. 86) que, "neste cenário, o liberalismo coloca-se como vitorioso, ante uma economia estatista que fracassou, ante a recusa do que esta doutrina considera indispensável: o mercado".

De forma que se apresenta como a única saída para a crise econômica, e traz como expressão político-ideológica o neoliberalismo, liberando a economia, as relações de trabalho da intervenção do Estado e o controle de qualquer forma de regulamentação (Oliveira, 2015). Portanto como pensar numa nova postura da gestão escolar ética e democrática frente a este cenário?

No entanto, para Freire (2001, p. 21):

A dimensão ética se restringiria apenas à competência do educador ou da educadora, à sua formação, ao cumprimento de seus deveres docentes, que se estenderia ao respeito à pessoa humana dos educandos. Falamos em ética e em postura substantivamente democrática porque, não sendo neutra, a prática educativa, a formação humana, implica opções, rupturas, decisões, estar com e pôr-se contra, a favor de algum sonho e contra outro, a favor de alguém e contra alguém.

Ainda para Freire (2001), “ a educação só poderia ser possível com uma profunda mudança na sociedade, da política (“politicagem"), da ética do cotidiano dos indivíduos e grupos sociais”. Pensando que a escola pode ser veículo de ensino para cidadania, Paro (2001, p. 10) considera que:

Nesse sentido, a cidadania, como síntese de direitos e deveres, constitui-se fundamento da sociedade democrática. A democracia é importantíssima no âmbito político; mas para efetivar-se, de fato, como mediação de uma vida social norteada por princípios histórico-humanos de liberdade, ela precisa impregnar toda uma concepção de mundo, permeando todos as instâncias da via individual e coletiva.

Desse modo diante das regras que regulam a sociedade, fazem-se necessários indivíduos que pratiquem a democracia, que exercitem a cidadania. Só há sociedade democrata com cidadãos democratas. Portanto a educação se torna importante para a democracia e para a cidadania. Ela propicia a apropriação da cultura e o desenvolvimentodo caráter histórico dos seres humanos (Paro, 2001).

Precisa-se através da escola, garantir uma educação voltada aos valores éticos parao desenvolvimento de uma sociedade melhor, onde a participação de todos nas discussões e tomada das decisões, proporcionada pela gestão escolar, propiciará ao indivíduo adquirir esses valores através da convivência e de sua atuação democrática dentro da sociedade. Mas para isso ocorrer a escola precisa ter objetivos, pautados fundamentalmente na formação da democracia.

\section{Considerações Finais}

Para a participação democrática na escola se efetivar, precisa levar em conta o modo de pensar e a forma de agir das 
pessoas que estão inseridas no ambiente escolar. Faz-se necessário então considerar que a escola tenha uma visão respeitosa pela comunidade, e a comunidade ter também condições de reconhecer a sua participação frente as decisões que precisam ser tomadas no cotidiano da escola. Percebe-se que a democratização da gestão escolar não vem ocorrendo de forma plena nas escolas.

Em uma sociedade capitalista a escola vem contribuindo para a preparação de sujeitos para atender as exigências desse mercado de trabalho, deixando de lado suas funções sociais relacionadas ao posicionamento ético e crítico diante da sociedade em que vivem. Portanto, se a gestão escolar atuar democraticamente, poderá auxiliar nesse combate, colocando em discussão a função social da escola e oportunizar práticas de que supere a desigualdade e injustiça social, promovendo que cidadãos sejam capazes de participar politicamente frente as situações e contradições presentes na sociedade atualmente.

Portanto é preciso pensar numa escola que se preocupa com a formação de determinados valores, atitudes e compromissos importamtes a vivência em sociedade, em educar para a democracia, e por ser um local privilegiado de diálogo, a escola deve contribuir com o fortalecimento político de seus usuários, propiciando mais participações coletivas e conscientes voltadas a valores, a construção de conhecimento e de uma sociedade melhor e mais justa.

Observa-se também de propor debates sobre o papel da gestão democrática frente a um estado neoliberal, discutindo os problemas que surgem no coditiano das escolas, e que de alguma forma interferem também no processo ensino aprendizagem. Propor esses debates tem como finalidade, favorecer e fortalecer ações mais participativas para a efetivação da gestão democrática nos espaços escolares. Entretanto, para trabalhos futuros, faz-se necessário uma análise com outros fatores a serem pesquisados, que envolvam a investigação das ações e decisões do coletivo, dentro da escola.

\section{Referências}

Alves, S. M. C., \& Barbosa , M. R. B. (2020). Gestão escolar democrática: dimensão diretiva aos processos educacionais significativos. Research, Society and Development, 9(4), el139942985.

Aquino, J. G. (1999). A questão ética na educação escolar. Boletim Técnico do Senac, 25(1), 2-13.

Aristóteles. (1973). Ética a Nicômaco. Trad. Leonel Vallandro e Gerd Bornhein Coleção Os Pensadores. Abril S.A. Cultural.

Brasil (1988). Constituição da República Federativa do Brasil. Senado Federal, Brasília.

Brasil.(1996). Lei $n^{\circ}$ 9.394, de 22 de dezembro de 1996. Dispõe sobre as diretrizes e bases da educação nacional. Diário Oficial da União, Brasília.

Brasil. (1969). Decreto-Lei $n^{\circ} 477$, de 26 de fevereiro de 1969. Define infrações disciplinares praticadas por professores, alunos, funcionários ou empregados de estabelecimentos de ensino público ou particulares, e dá outras providências. Brasília.

Bruno, L. (2011). Educação e desenvolvimento econômico no Brasil. Revista Brasileira de Educação, 16, $545-562$.

Cóssio, M. D. F. (2006). Gestão democrática da educação: retórica política ou prática possível. In: Camargo, Ieda de. Gestão e políticas da educação. Santa Cruz do Sul: EDUNISC.

Fernandes, M. D. E. (2018). Gestão Democrática da Educação no Brasil: A Emergência do Direito à Educação. Editora Appris.

Filho, A. A. J. \& Maciel, C. M. L. A. \& Monteiro, E. S. \& Nantes, E. A. S. (2019). Análise do cotidiano na gestão democrática escolar. Research, Society and Development, 9 (2), e48922029.

Freire, P. (2001). Política e educação. (3a ed.), Coleção Questões da nossa época, (23).

Gohn, M. G. (2019). Participação e democracia no Brasil: da década de 1960 aos impactos pós-junho de 2013. Editora Vozes.

Harvey, D. (2005). O neoliberalismo, História e implicações. Loyola.

Lima.,T. C. S. \& Mioto, R. C. T. (2007). Procedimentos metodológicos na construção do conhecimento científico: a pesquisa bibliográfica. Revista .katálysis. Universidade Federal de Santa Catarina (UFSC), 10.

Lukács, G.(2013). Para uma ontologia do ser social II. Boitempo.

Melo, G. N. (1993). Cidadania e Competitividade: Desafios Educacionais para oTerceiro Milênio. Cortez.

Oliveira, D. A. (2015) Gestão Democrática da Educação: desafioscontemporâneos. (11a ed.), Vozes.

Paro, V. H. (2018). Gestão escolar, democracia e qualidade de ensino. (2a ed.), Intermeios. 
Research, Society and Development, v. 10, n. 13, e196101321163, 2021

(CC BY 4.0) | ISSN 2525-3409 | DOI: http://dx.doi.org/10.33448/rsd-v10i13.21163

Paro, V. H. (2001). Escritos sobre Educação. Xamã.

Paro, V. H. (2016). Gestão Democrática da Escola Pública. (16a ed.), Cortez.

Pinheiro, C. M. O. (2015). Fórum Nacional em Defesa da Escola Pública e o princípio de gestão democrática na Constituição Federal de 1988. Dissertação (Mestrado em Educação) - Universidade Estadual Paulista, Faculdade de Filosofia e Ciências. Marília.

Silva, S. D. D. (2010). A influência neoliberal na educação. Monografia apresentada à faculdade de formação de professores UERJ, como pré-requisito para obtenção de grau de licenciada em pedagogia, sob a orientação do professor Dr. Jorge Antônio Rangel. UERJ.

Vásquez, A. S.(1996). Ética. (16a ed.), Civilização Brasileira.

Vieitez, C. G. \& Dal Ri, N. M. (2010). Gestão democrática na escola pública: Escola Construindo o Caminho. Educação Unisinos, 14, (2), 111-125

Vieitez, C. G. \& Dal Ri, N. M. (2011). A educação no movimento social: a luta contra a precarização do ensino público. Democratização e educação pública: sendas e veredas. EDUFMA, (1), 133-165.

Wood. E. M. (2011). Democracia contra capitalismo: a renovação do materialismo histórico. Tradução Paulo Cezar Castanheira. São Paulo: Boitempo. 